\title{
Modelo sistêmico integrado em gestão de estoques e compras na administração de resultado: o desafio financeiro no ressuprimento
}

\author{
Integrated systemic model in the management of stocks and purchases \\ in the administration of results: the financial challenge in the re-stocking
}

\author{
Mauricio Kalau Gonzales ${ }^{1}$
}

\begin{abstract}
Resumo
Quando se realizam compras na empresa, não somente se está repondo o estoque. Pode-se também obter uma série de vantagens financeiras para a empresa no contexto da administração do capital de giro. Porém, para que isto possa acontecer de forma positiva, há de existir uma política da empresa com esta visão e um sistema decisório que oriente o empresário. Propõe-se, neste trabalho, a confecção de tal modelo de decisão. Na revisão literária do assunto, vários pontos conflitantes foram expostos. Isto por se tratar não só do assunto compras, mas também dos aspectos interdepartamentais relacionados. Além disso, foram realizadas simulações de compras para verificar a aplicabilidade de fórmulas, como a de compras antecipadas, e demonstrar as vantagens e desvantagens da especulação. Por meio da investigação científica aqui formulada, pode-se observar, em balanços publicados, as diferentes estratégias de estocagem das empresas em períodos de incerteza, confrontados com períodos de estabilidade monetária no Brasil e os resultados conseguidos. Como resultado da aplicação do teste $t$ de student para duas amostras, verificou-se que nos tempos de inflação alta as empresas de forma geral, estocaram mais, aplicaram menos recursos em disponibilidades (caixa e bancos) e obtiveram significativamente mais lucros que as empresas nos períodos de baixa inflação, provavelmente porque o mercado financeiro rendia mais. Deixou-se a recomendação de que as empresas, ao se atualizarem frente às novas perspectivas do mercado, revejam o seu modelo de gestão em estoques e produção, promovendo o estabelecimento de condições para que toda a cadeia de produção(SCM) inserida no contexto seja administrada participadamente.
\end{abstract}

Palavras-chave: Compras. Sistema. Capital de Giro. Reabastecimento. Especulação. Gestão em SCM.

Abstract

When purchases are carried out in the company, it is not only to replace the stock. It is also possible to obtain several financial advantages for the company, to what the working capital management is concerned. However, in order to make it happen positively, the company must have a policy of such an understanding and a decisive system which guides the entrepreneur. It is proposed in this work the creation of such a model of decision. In the literary review about this subject, several conflicting points were explained because it dealt with not only purchases but also related interdepartmental aspects. Besides, purchases simulations were performed in order to verify the applicability of formulas such as those of the purchases made in advance as well as to demonstrate the advantages and disadvantages of speculation. By means of the scientific

\footnotetext{
${ }^{1}$ Professor do Departamento de Administração da UEL. Especialista em Metodologia do Ensino Superior - UEL. E-mail: mauriciokg@sercomtel.com.br. Site:www.uel.br/pessoal/mauriciokg
} 
survey herein formulated, it is possible to observe in balance sheets that were published, the different stocking strategies of the companies in periods of financial uncertainty, confronted with periods of monetary stability in Brazil and the results obtained. As a result to the application of the $t$ test to the student in two samples, it was observed that, in periods of high inflation, the companies in general stocked more, invested less in available resources (cash and banks), and obtained more profit than in periods of low inflation, probably because the financial market offered more advantages. It was recommended that the companies, as they update their system due to the new perspectives of the market, review their model of stocks and production management, fostering the establishment of favorable conditions so that all the related production chain (SCM) can be administered in a participatory way.

Key words: Purchases. System. Working capital. Re-stocking. Speculation. Management in SCM

\section{Introdução}

Antes de iniciar a discussão do tema proposto, faz-se necessário complementar o sentido e a abrangência das questões expressas no título, para que o leitor possa situar-se em relação ao campo da administração de empresas ao qual este trabalho concerne.

$\mathrm{Na}$ administração de uma empresa, notadamente privada, sempre existe, além da contribuição para a sociedade, o objetivo de lucro. Lucro este, na visão do empresário, quase sempre expresso pela rentabilidade financeira obtida na condução dos negócios após o incremento de políticas empresariais, seja pelo conhecimento que estas pessoas possuem em relação ao mercado, fornecedores, funcionários, leis e outras ou pelo sistema no qual está inserido. Enfim, o Know-how do negócio que está sendo gerido ou operacionalizado.

Justamente em função do Know-how, é comum a empresa estar sempre aprimorando-se naquilo que faz no sentido da administração. Na busca pelo aprimoramento nos negócios, não raramente os funcionários fazem cursos, participam de palestras sobre as áreas de atuação de cada um, de acordo com a necessidade da empresa e do objetivo do empresário. Este também, na medida do possível, atualiza-se naquilo que faz, e procura adquirir um conhecimento mais consistente na sua área de atuação.

A competitividade exige essa tomada de postura por parte das organizações e das pessoas que as dirigem, para que se possa alcançar e otimizar o lucro empresarial, necessário para manutenção e desenvolvimento da empresa.

A diversidade de empresas, os tipos de estrutura, as funções que exercem, os produtos que comercializam e os meios de produção, geram formas de administração muitas vezes com especificidades e peculiaridades que podem trazer o lucro ou não, em função de pormenores tratados no fluxo de trabalhos em um determinado período de tempo. Neste trabalho, o foco está sobre as compras que a empresa realiza e de que forma estas contribuem para trazer lucro em sua interação ao sistema empresarial, no seu conjunto de ações.

Alguns aspectos relevantes devem ser considerados por qualquer empresa que esteja repondo seu estoque ao realizar compras. Uma seqüência de decisões deve ser tomada no sentido de repor o estoque vendido, envolvendo informações, não só da área específica de compras, mas de outros departamentos também. Este cabedal de informações, se corretamente dirigidas e executadas, podem maximizar o resultado obtido: o lucro. Aqui, então, o sentido da palavra integrado: integrar as informações necessárias aos diversos setores da empresa relacionados às compras e estocagem de maneira conjunta e harmônica, visando ao melhor resultado possível.

Vale ressaltar que o resultado máximo está diretamente relacionado com a possibilidade de investir o mínimo de recursos naquele esforço e, com ele, obter o máximo de retorno possível no processo de compra efetuado. Dessa forma, o estoque vendido 
é reposto e os recursos são maximizados pelo uso racional.

Desde o momento em que é detectada a necessidade de reposição de uma mercadoria até o momento no qual a mercadoria reposta é entregue ao cliente, existe todo um movimento logístico, no sentido de movimentação de materiais. Embora seja um importante aspecto do gerenciamento, neste estudo estará sendo considerado apenas como meio de apoio, para obter o melhor resultado final.

Por não serem infinitos os recursos financeiros que uma empresa possui, ela deve saber tratá-los, inclusive porque existem custos sobre esses recursos. Mas, a empresa não tem só a área de compras para alocar recursos financeiros. Então a pergunta é: qual parcela dos recursos da empresa pode ser disponibilizada para que o comprador tome as decisões de reposição de mercadorias? E, mais importante: como deve ser sistematizada a prioridade nas decisões de compras da empresa para atingir o resultado esperado? Para responder essas perguntas, é necessário estudar todo o ciclo de capital de giro da empresa e sua relação com os estoques, a prioridade de produtos a comprar, as estratégias empresariais que podem modificar o perfil de compras da empresa, em função das decisões tomadas por seus dirigentes, os investimentos financeiros e de capitais que a empresa faz, as oportunidades de negócio no mercado, entre outros. Neste sentido cabe determinar que instrumentos de administração podem auxiliar a decisão do empresário. Em vista do exposto, este trabalho objetiva disponibilizar um sistema de checagem na tomada de decisão, que oriente, seqüencialmente, os aspectos mais relevantes das compras e estocagem, até o momento de quantificar o que comprar em um determinado período de tempo. Também se expõem as interações de informações que integram os sub-sistemas da empresa, utilizando o mínimo de recursos financeiros, para obter, consequentemente, o melhor resultado possível, sem deixar faltar mercadorias aos clientes. Também se leva em conta a contribuição das compras no processo de obtenção do lucro na empresa em uma visão de otimização da gestão, orientada a resultados.
Outro ponto que merece inicialmente ser salientado são as compras antecipadas. Não se trata de compras antecipadas relacionadas a entregas programadas ou compras estrategicamente negociadas com fornecedores (como as por cotas e/ ou contratuais), mas da aplicação da equação matemática das compras antecipadas e lote econômico de compras. Também se discute a relação das compras com a especulação, inclusive com exemplos comparativos.

O modo para atingir o melhor resultado nas compras em função do investimento em capital de giro e ter o maior retorno financeiro do capital investido, pode ser explicado por meio deste fato: antes de comprar uma mercadoria e colocá-la no estoque, para então ser comercializada, são confeccionados os pedidos de venda à vista para pagamento na entrega ou antecipado. De posse da informação de quanto foi vendido, compra-se do fornecedor com o maior prazo possível. Se a mercadoria for vendida com lucro, este se realizará imediatamente no recebimento da venda. Até pagar ao fornecedor e a outras despesas relacionadas, a empresa ainda poderá aplicar o recurso recebido, ganhando uma receita nãooperacional (financeira) neste período. Esta estratégia em compras também pode ser usada em momentos de necessidade para se alavancar o capital de giro, mas é sempre melhor não deixar a empresa chegar em um ponto financeiro no qual tal ação não possa ter o resultado desejado.

Portanto, inicialmente, deve-se perguntar se existe um meio que expresse a forma correta de realizar as compras, e se isso pode ser aplicado genericamente, para que o administrador de empresas em sua diversidade de situações e empresas realize a compra ideal.

Também deve ser esclarecido, no contexto desta pesquisa, que as aplicações financeiras e outras que a empresa venha a fazer, como a tomada de empréstimos, são parte de um contexto de sistema dinâmico e suas relações num sistema capitalista, de oportunidades, mas que também cobram juros sobre financiamentos realizados. Tais fatos são 
preliminarmente expostos, para que, assim, possa ser desenvolvido este trabalho, fundamentado em informações da práxis das empresas.

\section{Justificativa}

Para expor de uma maneira clara ao leitor, mesmo aos que ainda não têm conhecimento específico no assunto, é necessário esclarecer: cada área da empresa deve contribuir na obtenção e maximização dos resultados. A área de compras não foge a essa regra que Berger (2004, p.57) explica: “[...] ainda existem várias empresas que não exploraram todo o potencial existente em compras, que tipicamente representa entre 40 e $80 \%$ dos custos totais. Projetos com enfoque na inovação dos processos de compras têm gerado reduções de até 20\%". Mas o processo de otimização de compras interage com outras áreas da empresa, e esta, de modo sistêmico, interage com o ambiente. Então, no sentido de fazer a reposição dos estoques com a eficiência desejada, é necessário entender as inter-relações sistêmicas de compras com outras áreas que afetam o resultado esperado e saber o que do ambiente externo ao sistema ao interagir com a empresa afete a obtenção dos resultados, podendo ser otimizados com as ações que estão sob controle do seu administrador.

O objetivo empresarial na atualidade, no mundo capitalista, normalmente é medido através do lucro que as empresas obtém quando, sistematicamente, produzem e comercializam seus produtos. Porém, o lucro ou resultado financeiro positivo pode ser expresso em diferentes épocas durante um período. Também pode ser expresso unitariamente por item ou em conjunto. Geralmente, atribui-se o preço unitário de um produto, após analisar todos os custos envolvidos, direta e indiretamente, na empresa como um todo e rateia-se tais custos de forma padronizada para obter o custo de um produto. Para analisar o resultado mensal ou anual de uma empresa, ocorre o inverso. Agrupa-se todo o resultado individual de venda de cada produto, somando-o, mensal ou anualmente, juntamente com os outros resultados financeiros e extra - operacionais do mesmo período, para conhecer, no conjunto, qual foi o resultado geral apresentado pela empresa naquele período: o regime de competência. Por definição:

O processo de determinação do lucro e da posição financeira está relacionado com o regime de competência, distinto do regime de caixa. No regime de competência, o impacto dos acontecimentos sobre o ativo e o passivo é reconhecido nos exercícios em que os serviços são prestados ou utilizados, e não quando se recebe ou paga. Quer dizer, a receita é reconhecida quando obtida e as despesas são reconhecidas quando nelas se incorre, e não quando se paga ou recebe em dinheiro. (HORGREN, 1985 apud DI AGUSTINI, 1999, p.17)

Quando se administra a área de suprimentos de uma empresa, o responsável deve levar em consideração não somente esta possibilidade de aplicação, mas também o nível de sustentabilidade financeira da empresa. Mas a preocupação maior, nessas ocasiões, recai sobre as possibilidades de caixa da empresa, tratadas no seu fluxo.

Em um determinado período, o lucro ou o prejuízo perfaz a somatória dos esforços em um espaço de tempo. Tais esforços são, no contexto sistêmico, todas as possibilidades oferecidas nas operações da empresa e desta com o meio. Assim: "Sistema é auto - regulação. Deixa de ser sistema o que perde as condições de auto - regulação", explica Demo (1995, p.207).

Contudo, na rotina da administração de resultados, surge a possibilidade de especulação com os estoques. Muitas vezes, o administrador toma a decisão de comprar mais estoques de produtos não somente por antever a possibilidade de escassez no mercado, mas sim pela possibilidade de obter maior ganho na comercialização dos produtos naquele período. Especula-se:

Especulação - A redução da oferta, motivada pela quebra da safra gaúcha de 5,5 milhões para 4,5 milhões de toneladas, criou oportunidades para 
Modelo sistêmico integrado em gestão de estoques e compras na administração de resultado: o desafio financeiro no ressuprimento

especuladores. Os próprios produtores gaúchos procuraram reter a produção e tirar grande proveito da redução da safra. Apesar da disponibilidade do produto no mercado externo, o abastecimento continua ameaçado pelo baixo estoque nacional e porque só há verá colheita no início de fevereiro, a mais de seis meses. (CRISE..., 2003, p.12).

A prática da especulação, ainda que utilizada, tem restrições ao uso especificadas em lei. No Brasil, por exemplo, existe o Código de Defesa do Consumidor e outras leis que se referem ao assunto e o disciplinam. Neste caso, pode-se perguntar se os dirigentes empresariais sabem quais as consequiências da especulação, tomada como prática empresarial.

Para muitos, o ato de especular cotidianamente só é resultado de um desequilíbrio no sistema capitalista. Normalmente, esse resultado satisfaz somente ao especulador. Em Michaelis (1998, p.870), encontra-se, entre outras, a seguinte definição para especulação: "Operação comercial que visa não apenas ao lucro ordinário do ramo, mas, sobretudo aos das flutuações conjeturais do preço das mercadorias, ou se faz por uma transação que envolve riscos incomuns contra uma chance de lucro muito grande".

Cabe lembrar, a esse respeito, que a falta de mercadoria no mercado ou o aumento iminente de preço pode fazer a empresa reter mercadoria, com o objetivo de obter maiores ganhos futuros. Cabe porém, avaliar as vantagens e desvantagens dessa decisão. Outras vezes ocorre o inverso, ou sua prioridade na aplicação financeira ou equivalente no mercado, visando a melhores resultados do objetivo final da empresa, com a comercialização ou produção de seus produtos.

Isso ocorre porque se está trabalhando num ambiente sistêmico. Explica Demo (1995, p.204): "Há assim, na significação de sistema uma noção que se apresenta à de inter-relação entre as partes. É uma estrutura de partes satisfatoriamente distribuídas, que se associam e se completam." O autor ainda explica que essa inter-relação pressupõe o conceito de estabilidade por não poder existir em um ambiente de caos. Já para Hansen e Mowen (2003, p.55), “um sistema é um conjunto de partes inter-relacionadas que realiza um ou mais processos para atingir objetivos específicos". Qualquer sistema têm limites. Sua abrangência e inter-relacionamento com outros sub-sistema, definidos em função do melhor resultado, e das proporcionalidades, estão representadas, na empresa, pela apresentação das contas do balanço.

Externamente à empresa, no contexto dessa interrelação com o ambiente, existe a inflação. Simcsik (1992, p.540) expõe: "Inflação ocorre sempre que há um aumento de níveis dos preços com a conseqüente redução do valor real de uma moeda em relação a determinado padrão estável." Explica-se aí a inflação gerando custos, operacionais e financeiros, dos quais a empresa deve proteger-se. Simcsik (1992, p.540) continua: "Como conseqüência, possui um efeito corrosivo e de redução nos futuros valores de caixa, tornando os futuros investimentos de menor valor (em contrapartida, torna os investimentos atuais, principalmente em estoques, de maior valor...)."

$\mathrm{O}$ administrador, tanto nas pequenas como nas médias empresas, geralmente não dispõe de informações ou não conhece a melhor maneira para, de modo sistemático, conduzir as compras no ciclo operacional do capital de giro na gestão do seu negócio de forma equilibrada. É necessário, então, que se disponibilize a esse grupo de pessoas e demais interessados no assunto uma metodologia que especifique o fluxo de administração dos estoques em conjunto com os outros sub-sistemas da empresa. Um sistema lógico no qual se apresentem os fatores que influenciam tal administração e a sequiência de análise a ser feita para que o melhor resultado financeiro possível seja alcançado.

Não se trata, porém, da confecção de um construto de fatores para serem eletronicamente aplicados, como os ERP (Enterprize Resource Planning):

Um ERP é constituído por módulos que atendem às necessidades de informação de apoio à tomada de decisão de todos 
os setores da empresa, todos integrados entre si, a partir de uma base de dados única e não redundante. Podem ser entendidos como evolução do MRP II na medida em que controlam tanto os recursos diretamente utilizados na manufatura quanto os demais recursos da empresa. (CORRÊA et al., 1997 apud MENDES; ESCRIVÃO FILHO, 2003, p.277).

Trata-se de definir um método com o qual se possa, a partir do conhecimento da área de atuação da empresa, averiguar a tomada de decisão na área de compras e estoques, antes da decisão final em realizála. Com isso, poder-se-á ampliar a forma de gestão, da forma mais simples e eficiente possível, e aplicarse o bom senso na administração de compras de uma maneira própria e lógica, com base em um modelo sistêmico. Como os ERP necessitam de grande aporte financeiro para implantação, é necessária uma reestruturação da empresa para seu uso e sua indicação então deve levar em consideração o porte da empresa entre outras características para sua implantação.

Portanto, neste trabalho, averiguar-se-á a relação entre o que teoricamente se pratica nas empresas e o que pode vir a ser praticado, sob a perspectiva de observação histórica e dos resultados financeiros em sua relação com níveis de estocagem, sem usar de academicismos exagerados.

Mas não se pode negar que, no campo das ciências, a evolução é constante, bem como na administração de empresas. O nível de tecnicismo não pode ser aplicado em todo tipo de empresa, mas ele é de extrema necessidade e aplicabilidade em empresas específicas. Um bom exemplo é a ciência agrária, na qual a agricultura de precisão tem dado mostras do uso de várias técnicas científicas para atender a determinado propósito. Porém, o seu uso não está sendo explorado em muitas propriedades agrícolas em função dos custos envolvidos, embora este setor tenha evoluído muito e, constantemente, como um todo, desde as últimas décadas do século $\mathrm{XX}$.
A tomada de decisões envolve conhecimento de parâmetros. Níveis de estoques e outras relações numéricas empresariais acerca do assunto estarão sendo garimpadas e mostradas de uma forma técnica e estatística. Por não haver uma formulação taxonômica numérica neste nível operacional, os resultados apontados poderão ser base para outros estudos. Chiavenato (1993, p.837) define assim nível operacional: "É o nível no qual as tarefas são executadas e as operações realizadas: envolve o trabalho básico relacionado diretamente com a produção dos produtos ou serviços da organização".

Está sendo feita aqui uma revisão do referencial teórico sobre os cálculos do Lote Econômico de Compras (LEC), confrontando-o com a necessidade de resultado da empresa em sua relação com o capital de giro. Isso é necessário para que cada setor da empresa se caracterize como uma fonte de recursos, racionalizando a administração e contribuindo para o resultado final.

\section{Contexto Bibliográfico}

Nas considerações atuais a cerca da quantidade de compras em cada período específico, visando à reposição de mercadorias nos estoques, levam-se em consideração diversos fatores que, se estrategicamente bem adotados, podem levar à realização de lucro na comercialização de produtos.

Em termos de administração de empresas como ciência, desde os estudos mais elementares e primários conhecidos como os estudos de tempos e movimentos de Taylor, (apud CHIAVENATO, 1993), os avanços conseguidos nem sempre fizeram parte das rotinas de trabalho das empresas, no âmbito de toda a cadeia de produção. Porém, é interessante ressaltar que o empresário atento sempre usa o desenvolvimento contínuo para melhorar suas atividades, utilizando-se dos mesmos princípios de racionalização elencados por Taylor. Com discernimento neste campo de aplicação, pode ele avaliar que muitas teorias atuais, para muitos, não passam de "teorias". 
Didaticamente, dividiu-se esta revisão bibliográfica em três partes: Os aspectos relacionados ao sistema e suas inter-relações; o gerenciamento das compras; e os modelos de cálculo associados. Serão discutidos separadamente, porém de forma integrada e complementar.

\section{Aspectos sistêmicos}

Os pontos específicos enunciados aqui e outros relevantes também são citados para levar o a compreender as características de competitividade em que se insere a administração da empresa moderna na sua relação com o ambiente. Lembrese, a esse respeito, que a competitividade esta voltada para a lucratividade, medida de produtividade da razão entre o lucro e as vendas. Genericamente, produtividade, segundo Simcsik (1993, p.538), é representada pela fórmula:

$$
\begin{aligned}
& \text { Valor da produção } \\
& \text { Valor dos recursos } \\
& (\mathrm{RHu}+\mathrm{RMa})
\end{aligned}
$$

A esse respeito, Smith (1993, p.1) afirma: “ A maioria das definições de produtividade inclui lucratividade, eficiência, efetividade, valor [...]".

Em relação à estocagem inicialmente, cita-se um esclarecimento na visão de Hansen e Mowen (2003, p.749): "Tradicionalmente, estoques são mantidos para que a empresa possa tirar vantagem de descontos em quantidades e proteger-se contra futuros aumentos de preços dos itens comprados."

Via de regra, a administração de compras está voltada para esta linha de ação. Mas, hoje, os desafios e as contingências administrativas impõem a adoção de outras estratégias que o autor acima também observa.

Muitas dessas estratégias, importantíssimas e relevantes na tomada de decisão, referem-se à estocagem: giro dos estoques de mercadorias; capacidade de armazenagem; capacidade financeira de compra e manutenção dos estoques; negociação com fornecedores; previsões de demanda, custos de produção, entre outros. Além disso, e após muitos esforços, muito se desenvolveu no modal logístico que serve de infra-estrutura para operacionalização de indústrias e empresas em geral no Brasil como um todo, principalmente em áreas de maior desenvolvimento urbano e nas capitais. Ressalta-se isso porque, muito freqüentemente, esses ganhos em conhecimento sobre Supply Chain Management (SCM) não são repassados, aproveitando-se a máxima eficiência em intermodalidade, como benefício à toda a cadeia de transformação e venda de um produto, muito embora os estudos sobre gerenciamento e cadeia de produção já estejam bastante avançados.

Para ilustrar, apresenta-se a seguinte figura, ilustrando uma cadeia de produção e venda.

Geralmente, a distribuição de lucro é desigual para os participantes, dentro de uma cadeia de produção,

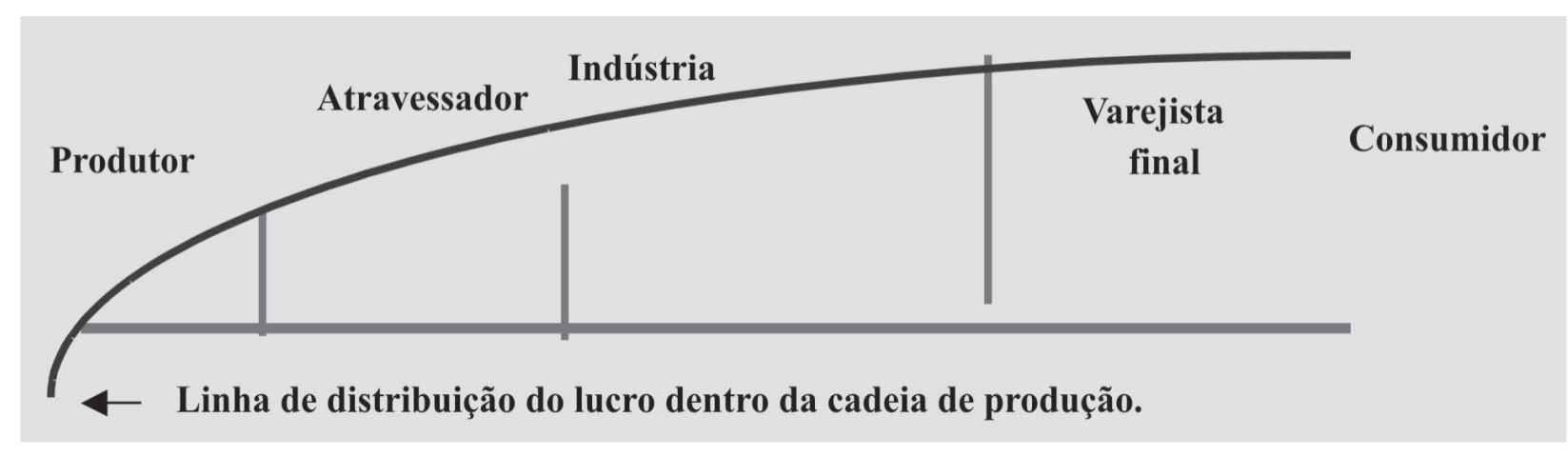

Figura 1. Área de distribuição de lucro por setor 
na abordagem tradicional de compras e estocagem. Aqui esse lucro demonstra para o produtor a menor parcela de resultado. Isso traz uma pressão enorme para os esforços de capital de giro e seu gerenciamento, trazendo, muitas vezes, o resultado negativo, o prejuízo.

Mas isso geralmente não ocorre na modalidade de estocagem com o Just-In-Time (JIT), na qual existe uma relação de dependência, coexistência e comprometimento com a produtividade. Moura (1999, p.13) traz uma definição para Just-in-Time: "O "Justin-Time" é uma abordagem disciplinada para melhorar a produtividade e a qualidade total, por meio do respeito pelas pessoas e a eliminação de perdas". Tem-se, no final da cadeia, o resultado da eficiência de forma geral, com uma distribuição mais equilibrada, nos valores agregados ao produto, para cada participante da cadeia de produção e de vendas. $\mathrm{Na}$ abordagem tradicional, como mostra a figura acima, esse comprometimento pode não existir, pelo fato de um participante do elo produtivo não ser produtivo. Assim, os outros integrantes podem não querer se co-responsabilizar pela sua ineficiência ou estrutura inadequada, mas sim para usufruir seu esforço. Isso pode ocorrer em qualquer elo da cadeia.

Porém, também é de fundamental importância salientar que há fatores a serem considerados nas decisões empresariais visando às compras. Esses fatores sempre contam com a existência de um mercado financeiro ativo e outras possibilidades de aplicações de numerários que tenham rendimento financeiro para operações monetárias realizadas. Cabe explicar que a cada aplicação corresponde um risco inerente. Escreve inicialmente Perez Junior (1997, p.174): “ Percebe-se, no mundo de hoje, diversas características e tendências que afetam, de forma muito relevante, o mundo dos negócios.” $\mathrm{E}$ continua:

Essas tendências, cada vez mais agudas, exigem do administrador uma postura voltada para o aperfeiçoamento permanente das operações da entidade, identificando em tempo hábil as necessidades de mudanças nos sistemas implantados, na tecnologia aplicada e nos processos existentes. Assim, importante também é dotar a empresa e seus funcionários de uma cultura que entenda as necessidades das mudanças e as assimile sem grandes dificuldades, já que é de responsabilidade do gestor o gerenciamento de tecnologias e pessoas para a obtenção de resultados. (PEREZ JUNIOR, 1997, p.175 ).

Uma das características que afetam diretamente o resultado financeiro de uma empresa é a administração de seus estoques. Afirma Rodrigues (1993, p.1): "É necessário termos domínio sobre a formação de nossos estoques, pois somente assim conseguiremos atingir os giros de estoques pretendidos e determinados por nossos parâmetros de dimensionamento". No contexto da administração, estão relacionados diversos sistemas que interagem no objetivo de se produzir resultado no momento do ressuprimento de mercadorias. Na administração do capital de giro durante o ciclo operacional da empresa, insere-se a formulação de regras, limites ou parâmetros para compras, visando a determinados fins, inclusive na área de estocagem. Explica-se:

É importante que todos os responsáveis pelas compras junto a fornecedores sejam envolvidos e engajados com a otimização do caixa da empresa. Caso contrário, uma ótima negociação no âmbito de uma compra poderá representar um verdadeiro desastre para o capital de giro da empresa. (DI AGUSTINI,1999, p.55).

Santi Filho (1993, p.70) define assim: "Denominamos CDG - Capital de Giro a parcela dos recursos próprios da empresa que se encontra disponível para aplicação."

Porém, fatores diversos à análise financeira compõem a função do administrador ao realizar as compras: "A questão de saber se devemos estocar um item, embora seja anti - econômico fazê-lo, a fim de prestar melhor serviço ao freguês, representa uma 
decisão mais difícil, porque freqüentemente é impossível atribuir um exato valor em dinheiro à satisfação do cliente." (ALCURE, 1982, p.19).

Mas a afirmação acima contém uma variável não quantificável financeiramente na contribuição para compras, quando se deseja ter o melhor resultado financeiro num determinado período de vendas. Por isso, a maioria dos itens, que são considerados para se tomar uma decisão de compras nas empresas, leva-se principalmente em consideração, depois de se saber o que comprar, os custos financeiros envolvidos e a capacidade financeira da empresa na sua realização, além de sua quantificação em termos de retorno. Como afirma Rodrigues (1993, p.2): “É necessário que todos tenham uma idéia clara do que representam os custos financeiros de manter altos estoques." Acrescenta-se a este contexto:

"são apresentados os principais fatores que estão motivando as cadeias de suprimento a reduzir continuamente seus níveis de estoque: uma maior diversidade no número de produtos e mercados atendidos, o elevado custo de oportunidade de capital e o crescente foco gerencial no controle e redução no grupo de contas pertencentes ao Capital Circulante Líquido”. (WANKE,1999,).

Para alguns itens, durante um determinado período de tempo, uma empresa pode vender conscientemente produtos que unitariamente não apresentam lucro, mas contribuem com algum percentual na diluição dos custos fixos, o que possibilita um lucro mensal juntamente com os outros produtos vendidos naquele período. Usa - se o conceito de margem de contribuição e ele se aplica para empresas que possuem sistemas de custeio bem estruturados e confiança na forma de sua aplicação. Kotler (1990, p.297) mostra uma metodologia para formação de preço de venda, mas ressalva que "[...] o modelo pressupõe uma empresa maximizadora de lucro que conheça suas funções de demanda e custos em relação ao produto em questão." O Código Brasileiro de Defesa do Consumidor, inclusive, trata a observância aos preços fixados. Ao comentar o assunto, Grinover e Denari (1997, p.74) afirmam “[...] porquanto muitos pequenos empresários ainda não teriam aprendido a formar preços em uma economia estabilizada". Os mesmos autores salientam que o Código de Defesa do Consumidor garante o direito do consumidor "[...] a liquidação antecipadamente do débito, total ou parcialmente, mediante redução proporcional dos juros e demais acréscimos." Esse fato é primordial para o empresário, no sentido de alertá-lo para a importância da formação do preço de venda do produto, com base em sistemas de custeio confiáveis e que levem em consideração também, nas vendas à prazo, o custo do financiamento ao cliente.

Para se atingir o ponto no qual existirá o maior retorno financeiro provável na quantidade a ser comprada de um determinado produto e quantificar quanto comprar neste período em detrimento de outras aplicações, os administradores fazem uso de diversos cálculos, associados a várias informações que podem culminar com a realização de um resultado, ( melhor ou pior) na administração dos estoques. Tal tarefa, para ser conduzida de forma responsável, não é das mais fáceis, pois ela envolve além das questões internas da empresa, o mercado fornecedor e a alta variação do mercado comprador, já mostrando uma visão de dependência do sistema externo à empresa e, na empresa, a dependência entre os setores. Rodrigues explica:

Pensamos que é possível atingir o giro de estoques que quisermos, desde que estejamos dispostos a pagar o preço disso. Bastaria apenas transferir o nosso problema para o fornecedor - ele estocaria para nós - e nosso resultado em termos de estoque seria magnífico. Porém, o resultado global seria desastroso. Tudo isso reforça a idéia de que é necessário que desenvolvamos um trabalho em equipe, para buscar a melhor situação. (RODRIGUES,1993, p.3) 
Outros problemas relativos à administração de estoques podem ocorrer. Para Moura (1999, p.6): “[...] pode-se antecipar o estoque para problemas previsíveis, mas quando a previsão não se realiza e o estoque fica parado, a perda é muito grande". Nesse caso, a perda financeira em relação à compra de outro item e do próprio produto na estocagem. Rodrigues (1993, p.6) ainda explica: "Alguma informação externa ou interna ao ambiente da fábrica nos leva a acreditar que formando estoque daquele item, obteremos melhor resultado em termos de lucro para a empresa". Em função disso, é necessário existir e se saber qual o limite nas compras, de acordo com a capacidade disponível de capital de giro da empresa no ciclo operacional, decidido estrategicamente pelos seus dirigentes, mas de acordo com uma metodologia sistêmica de cálculo e decisão. Afirma Smith (1993, p.3): "Os dados obtidos ao longo de períodos variados refletem mudanças, ilustram tendências, formam bases para previsões ou podem ser usados de outras maneiras significativas."

No tocante ao relacionamento com o fornecedor, há diversos fatores que devem ser analisados antes do momento da compra. Eles dizem respeito à negociação e também são decisivos para se fazer uma boa compra.

No momento de se calcular o quanto comprar, todas as informações do mercado comprador e informações pertinentes ao ato da compra devem ser mensuradas de forma conjunta. Outra questão volátil atualmente é a carga fiscal de impostos que incide sobre um produto, e está relacionada ao ato das compras: Como exemplo, a guerra fiscal:

Desde o final de setembro, antes do governo proibir a concessão de benefícios fiscais, via decreto, Minas Gerais e Rio Grande do Sul zeraram o Imposto sobre Circulação de Mercadorias e Serviços ( ICMS ) recolhido no leite longa vida e ainda concedem um crédito presumido de $11 \%$ nas operações interestaduais. Com isso ficou mais barato para as redes varejistas de supermercados comprar o leite em outros estados, onde podem se ressarcir desse crédito. (CASADO, 2003, p.5).

Pelo fato de os aplicadores de recursos com frequiência obterem informações privilegiadas em relação ao mercado consumidor e fornecedor, surgem oportunidades de compras e a possibilidade de especularem com recursos, visando somente ao maior lucro possível no menor período, inclusive nas aplicações em áreas que a empresa não atua operacionalmente. Por falta de conhecimento, muitos empresários deixam de aplicar recursos na própria empresa, na qual o retorno, em termos de organização, poderia ser melhor.

Um exemplo é o programa de Gestão Baseada em Valor (GBV).

Todas as equipes de unidades de negócios receberam cerca de um dia e meio de treinamento em conceitos básicos: como calcular a métrica de lucro econômico, como desenvolver propulsores fundamentais de valor para um determinado centro de valor menor do que a unidade organizacional e como interpretar os resultados. Houve ainda sessões adicionais de três dias de duração voltadas para as funções especializadas. O pessoal de marketing, por exemplo, concentrou-se em suprimentos, demanda e análise de preços, além de aprender como vincular essa análise aos conceitos de lucro. A equipe de finanças estudou modelos de cálculos informatizados, análise de estrutura de custo e benchmarking. (HASPESLAGH; NODA; BOULOS, 2001, p.108).

Em relação à utilidade de métodos de previsão de vendas, salientam-se nas áreas nas quais a previsão é especialmente útil, entre elas:

[...] Finanças - no estabelecimento de orçamentos, na previsão de capital de giro, nas previsões de caixa e nas previsões de receitas e despesas. [...] 
Produção - no planejamento da produção e no controle dos estoques. [...]. Compras - no planejamento de compras, a fim de obter preços favoráveis, na manutenção racional de estoques, evitando a imobilização excessiva de capital ou a falta de matérias-primas para a produção. (PENTEADO FILHO, 1988, p.20).

Na hora de realizar uma compra, é necessário, de antemão, definir a forma como as compras na empresa serão operacionalizadas e qual a base para sua decisão.

As demonstrações financeiras que se expressam no balanço patrimonial e de resultados podem ser fontes de informação para tomada de decisão. Escreve Franco (1989, p.266) "[...] coeficiente é a comparação de cada um dos elementos patrimoniais com o conjunto de que faz parte (patrimônio)". Porém, na tomada de decisão para compras, elas são apenas mais um item a ser considerado pela empresa.

Então, a questão que se apresenta é: que sistema pode ser utilizado, a fim de que, por meio de cálculos e análises qualitativas, seja contemplado o maior número de aspectos inerentes aos atributos das compras antes que as mesmas sejam efetuadas? A resposta é: as compras sistematizadas, pois de acordo com Rodrigues (1993,p.2): "os profissionais de outras áreas, que não sejam da administração de materiais, geralmente não possuem informações acerca de maneira pelo qual, maiores giros de estoque podem influir no resultado financeiro de uma empresa."

Fica necessário que toda a cúpula de decisão da empresa esteja adequadamente informada sobre qual é o método empregado no processo de compra e que todas as áreas responsáveis pela tomada de decisão estejam em sincronia na obtenção dos objetivos propostos, usando a mesma metodologia. A esse respeito, Smith (1993, p.9) enumera: "Os resultados da medição são importantes porque podem ser interpretados e eventualmente tornar-se a base da mudança ou dos esforços de melhoria". E também se deve considerar o que Chehebe (2002, p.26) diz: “ Na prática, o delineamento do contorno do sistema a ser estudado deve ser realizado com extremo cuidado, pois somos limitados pelos recursos financeiros e pelo tempo." Em resumo, pode-se afirmar que a informação de qualidade é primordial para uma tomada de decisão correta e sistêmica, na empresa, por parte dos seus dirigentes.

\section{Modelos de cálculos}

Fórmulas matemáticas que auxiliam a tomada de decisão do administrador podem ser usadas, a partir do seu conhecimento e das conseqüências que os resultados apresentados terão sobre o capital de giro da empresa, fluxo de caixa e outros contextos sistêmicos. Como, por exemplo, as que se seguem:

Fórmulas de lote econômico (LE) são mostradas por diversos autores, mas quase sempre resumemse à Amner (1979, p.215) ou a uma variação dela:

Acontece que o administrador, se for aplicar tal fórmula como único meio de cálculo para um lote de compras, irá deparar-se com algumas condições que tornam o seu uso inviável, atualmente na maioria das situações embora, didaticamente, esta fórmula seja ensinada. Para Hansen e Mowen (2003, p.739), esta é: "Quantidade Econômica de Pedido (EOQ ): O Modelo Tradicional de Estoques." Outra questão é que, na sua aplicação, além de a empresa ter que

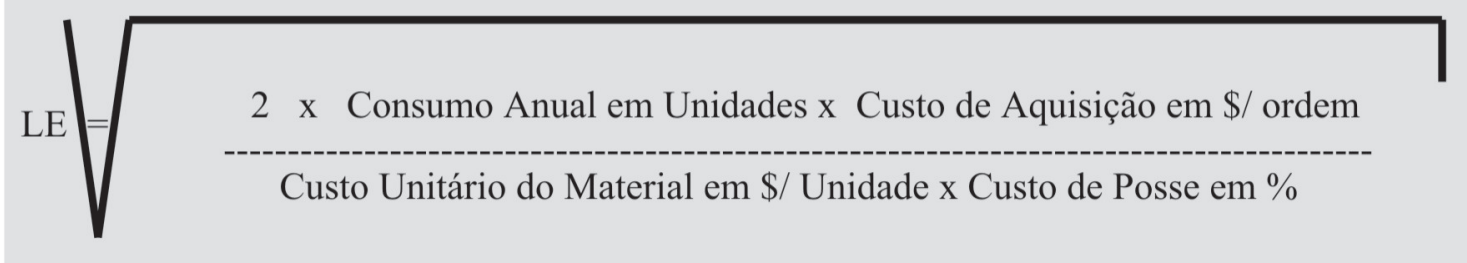

Figura 2. Fórmula de Amner para LE 
possuir uma grande quantidade física de área disponível, dependendo do tamanho do item para armazenamento, ainda terá que ter capital de giro para fazer a compra e mantê-la no estoque até sua venda. Isso se verifica se as vendas realizadas para aquele período forem iguais ou maiores que o previsto na base de cálculo, que geralmente é de um ano, com os custos de posse correspondentes. Também se deverá partir do princípio que o fornecedor não exercerá o seu direito de estipular um valor mínimo ou quantidade de produtos em um pedido para vender ou fazer a entrega da mercadoria. Além disso, a empresa fornecedora deverá ter a capacidade de manter um fornecimento regular de produtos à disposição para todos os seus clientes, não modificando o preço da mercadoria neste período.

Multiplique agora este procedimento em uma empresa que tem 9261 itens no seu estoque ou mais, por exemplo, ou quando se fabrica tal número de produtos. Torna-se necessário, então, ter outros parâmetros nas compras. Conforme explica Rodrigues (1993, p.2): "Podemos enxergar o estoque e medi-lo de três maneiras; em função da variedade de itens, do volume de material e do valor dos materiais estocados". Acrescenta-se a essas informações o lucro potencial, calculado com informações estruturadas em sistemas de custeio e formação de preço de venda, sendo este gerado na venda de cada produto. Essa informação pode mudar totalmente a decisão a cerca do modelo de compras a ser realizado. Contudo, quando se fala de parâmetros para estocagem, principalmente financeiros, a forma de administração de cada produto não é igual: um produto pode unitariamente custar pouco e outro custar mais. A expectativa de retorno financeiro, comparativamente às aplicações financeiras, em função da forma de estocagem e controle para reposição, será menor para os produtos de pequeno valor e maior para os de maior valor. Também cabe considerar o custo do pedido e dos trabalhos de recepção e armazenagem correlatos, no ressuprimento dos estoques, sendo comum o método de duas gavetas para reposição de pequenos itens de pouco valor.
A fórmula apresentada anteriormente de LE apontará, via de regra, para a compra de uma quantidade de materiais suficiente para abastecer a empresa durante o consumo de alguns meses. Questiona-se também, na aplicação de tal fórmula, se os materiais comprados forem perecíveis não podendo ser estocados durante o tempo de validade do produto. O resultado da aplicação de tal fórmula, nessas condições, é inviável.

Essas fórmulas matemáticas, utilizadas pelos administradores, mostram o quanto é mais vantajoso fazer um investimento num período de tempo em detrimento de outro em estoques, consideradas apenas suas variáveis, e não todo o dinamismo que as compras representam no conjunto da empresa. É necessário, ao administrador, muitas vezes, o uso da sua intuição para decidir.

Há ainda a possibilidade do uso da fórmula de compras antecipadas, principalmente por ela ser de fácil aplicação e mais simples que a do LEC (Lote Econômico de Compras). Mas quando da aplicação de tal fórmula, é necessário que antes se façam algumas ponderações, além das que foram citadas anteriormente acerca dos tipos de produtos em questão, inclusive a respeito da ótica da especulação. Porém, se o produto só existe para comercialização num determinado período de tempo, é conveniente saber se a quantidade comprada se esgotará como o previsto. Isto para não se guardar um estoque que somente irá ser consumido na próxima safra ou período sazonal; ou que se perderá por falta de consumo. Um exemplo são os produtos de confecção, para consumo em determinados período do ano, comercializados em função da moda, estação climática ou evento. Sorvetes também se incluem neste exemplo, para algumas regiões do Brasil. Apresenta-se a fórmula de compras antecipadas.

\section{Compras antecipadas: $\mathbf{m}=\mathbf{k} / \mathbf{j}$}

$\mathrm{m}$ (em meses de consumo)

Escreve Machline (1981, p.7): "Nessas condições, se chamarmos $\mathrm{k}$ o aumento percentual previsto do preço da mercadoria e $\mathrm{j}$ a taxa mensal aparente de juros (incluindo-se nela a taxa mensal de armazenamento físico e seguros), é fácil provar ser 
conveniente comprar antecipadamente a seguinte quantidade $\mathrm{m}$ “.

Em comparações com o Modelo de NADDOR e WEIL, Fensterseifer (1986, p.8) resume compras antecipadas com a seguinte equação $\mathrm{Q}=\mathrm{p} / \mathrm{i}$, correspondente à mesma formulação de Machline.

O componente financeiro usado como parâmetro nestas fórmulas normalmente é a percentagem de juros que o mercado de capitais paga para aplicações, em espécie, no período.

Em artigo à revista Exame, Bordokan (1983, p.52) discute sobre o retorno do investimento em estoque. Sem citar a fórmula de compras antecipadas expostas acima, dá um exemplo de sua aplicação, usando o mesmo raciocínio. E ainda comenta:

Outra concepção errônea que se costuma ter, porém menos evidente, é a de que quando os preços de venda de produtos estocados aumentam o lucro também aumenta. Ou seja, além do erro e se achar que a manutenção de estoques elevados é uma garantia contra a inflação, existe a concepção de que, se os preços de venda aumentarem, o estoque gerará lucro proporcional ao aumento de preços. (BORDOKAN, 1983, p.53).

O que foi dito justifica-se pelo fato de existirem outros custos relacionados à manutenção de estoques. Entre eles, e principalmente, está o custo de Tabela 1. Classificação ABC Comparativa obsolescência de produtos em função do desenvolvimento tecnológico, mais acentuado para muitos produtos atualmente. Arnold (1999, p.274) cita os custos de armazenagem: "[...] Custos de capital, Custos de armazenamento e Custos de risco (Obsolescência, Danos, Pequenos furtos e Deterioração)". Esses custos foram quantificados por Zermati (2000, p.31) para economias estáveis:

Os encargos financeiros recaem sobre as somas investidas em stocks; são juros dos empréstimos feitos sob diversas formas para financiar as compras; geralmente a taxa de juros, que era aproximadamente de $6 \%$ a $7 \%$ em 1960, passou para 14\% - 15\% em 1970 , atingiu $16 \%$ a $18 \%$ no início dos anos 80 e situa-se perto dos $10 \%$ a $12 \%$ desde o início dos anos 90.

Há ainda o risco de se ter problemas com o fisco. A seguir, apresenta-se uma tabela contendo resultado comparativo nas compras, utilizando-se os modelos de classificação ABC tradicional e o modelo com o conhecimento do lucro provável do produto, resultando em diferentes prioridades nas compras e em reflexos na administração do capital de giro.

\begin{tabular}{lr|l|l|l|l|l|l|l|l}
\hline \multicolumn{2}{l|}{ It. P.Um.\$ } & Cons.Mês & Luc.Unit. & $\mathrm{ABC}$ CxL & Clas.c/L & Prio.ABC & $\mathrm{ABC}$ CxP & Clas.s/L & Prio.ABC \\
\hline 01 & 500 & 100 & 40 & 4.000 & 15.600 & 19 & 50.000 & 270.000 & 24 \\
02 & 280 & 50 & 25 & 1.250 & 14.400 & 26 & 14.000 & 225.000 & 26 \\
03 & 1.920 & 20 & 70 & 1.400 & 9.000 & 14 & 38.400 & 200.400 & 14 \\
04 & 4.250 & 10 & 120 & 1.200 & 8.000 & 23 & 42.500 & 169.600 & 23 \\
05 & 6.780 & 5 & 180 & 900 & 7.200 & 22 & 33.900 & 120.000 & 8 \\
06 & 1.200 & 11 & 60 & 660 & 6.760 & 20 & 13.200 & 110.500 & 13 \\
07 & 400 & 120 & 32 & 3.840 & 6.500 & 13 & 48.000 & 105.000 & 25 \\
08 & 300 & 400 & 15 & 6.000 & 6.000 & 12 & 120.000 & 100.000 & 12 \\
09 & 150 & 150 & 7 & 1.050 & 6.000 & 8 & 22.500 & 89.000 & 22 \\
10 & 120 & 250 & 8 & 2.000 & 6.000 & 24 & 30.000 & 52.500 & 16 \\
11 & 100 & 500 & 5 & 2.500 & 5.200 & 17 & 50.000 & 50.000 & 1 \\
12 & 200 & 500 & 12 & 6.000 & 4.400 & 31 & 100.000 & 50.000 & 11 \\
13 & 221 & 500 & 13 & 6.500 & 4.200 & 16 & 110.500 & 50.000 & 15 \\
14 & 334 & 600 & 15 & 9.000 & 4.000 & 1 & 200.400 & 50.000 & 27
\end{tabular}


Gonzales, M. K.

\begin{tabular}{|c|c|c|c|c|c|c|c|c|c|}
\hline 15 & 1.000 & 50 & 20 & 1.000 & 3.840 & 7 & 50.000 & 48.000 & 7 \\
\hline 16 & 75 & 700 & 6 & 4.200 & 3.000 & 30 & 52.500 & 42.500 & 4 \\
\hline 17 & 50 & 800 & 6,5 & 5.200 & 2.500 & 11 & 40.000 & 40.000 & 17 \\
\hline 18 & 22 & 1.000 & 13 & 1.300 & 2.100 & 25 & 22.000 & 38.400 & 3 \\
\hline 19 & 21 & 1.200 & 13 & 15.600 & 2.000 & 10 & 25.200 & 36.000 & 30 \\
\hline 20 & 31 & 520 & 13 & 6.760 & 1.800 & 21 & 16.120 & 33.900 & 5 \\
\hline 21 & 44 & 450 & 4 & 1.800 & 1.700 & 27 & 19.800 & 30.000 & 10 \\
\hline 22 & 99 & 900 & 8 & 7.200 & 1.400 & 3 & 89.100 & 25.200 & 19 \\
\hline 23 & 106 & 1.600 & 5 & 8.000 & 1.300 & 18 & 169.600 & 22.500 & 9 \\
\hline 24 & 270 & 1.000 & 6 & 6.000 & 1.250 & 2 & 270.000 & 22.000 & 18 \\
\hline 25 & 350 & 300 & 7 & 2.100 & 1.200 & 4 & 105.000 & 19.800 & 21 \\
\hline 26 & 125 & 1.800 & 8 & 14.400 & 1.050 & 9 & 225.000 & 18.000 & 31 \\
\hline 27 & 250 & 200 & 8,5 & 1.700 & 1.000 & 15 & 50.000 & 16.120 & 20 \\
\hline 28 & 180 & 40 & 9,7 & 388 & 900 & 5 & 7.200 & 14.000 & 2 \\
\hline 29 & 135 & 50 & 9,9 & 495 & 660 & 6 & 6.750 & 13.200 & 6 \\
\hline 30 & 600 & 60 & 50 & 3.000 & 495 & 28 & 36.000 & 8.000 & 32 \\
\hline 31 & 225 & 80 & 55 & 4.400 & 388 & 29 & 18.000 & 7.200 & 28 \\
\hline 32 & 400 & 20 & $(-3)$ & $(-1.200)$ & $(-1.200)$ & 32 & 8.000 & 6.750 & 29 \\
\hline
\end{tabular}

Nessa tabela, se classificarmos os itens de 1 a 8 como prioridade A, 9 a 18 como prioridade B e 19 a 32 como prioridade $\mathrm{C}$, ter-se-á o seguinte resultado para uma compra mensal.

Tabela 2. Resumo de classificação ABC.*

\begin{tabular}{|lc||cc|}
\hline \multicolumn{1}{|c||}{ Classificação tradicional } & \multicolumn{2}{c|}{ Classificação c/ Prev. De Lucro } \\
A & $1.300 .500,00$ & A & $935.920,00$ \\
B & $510.500,00$ & B & $789.197,00$ \\
C & $272.670,00$ & C & $358.250,00$ \\
& & & \\
TOTAL & $2.083 .670,00$ & & $2.083 .367,00$ \\
\hline
\end{tabular}

Valores expressos em unidades monetárias

Se consideramos um lote de compras mensal, à primeira vista, a diferença do lote mensal na classificação tradicional não parece ser significativa. Mas, se considerarmos uma mudança na freqüência de entregas dos produtos A (de uma para quatro entregas ao mês), dos produtos B (de uma para três entregas) e dos produtos $\mathrm{C}$ (de uma para duas entregas), o reflexo na estrutura de caixa será sensivelmente diferente, supondo-se que o pagamento seja feito num período entre 15 e 40 dias a partir da data da entrega.

Tabela 3. Demonstrativo de fluxo de caixa comparado*.

\begin{tabular}{|c|c|c|c|c|c|}
\hline \begin{tabular}{|l} 
Mod./Dias \\
Clas.Trad. \\
Clas.c/L
\end{tabular} & $\begin{array}{l}15 \\
1.041 .835 \\
338.085\end{array}$ & $\begin{array}{l}22 \\
116.990 \\
\end{array}$ & $\begin{array}{l}25 \\
131.532 \\
\end{array}$ & $\begin{array}{l}30 \\
338.085 \\
\end{array}$ & 116.990 \\
\hline $\begin{array}{l}\text { Mod./Dias } \\
\text { Clas.Trad. } \\
\text { Clas.c/L }\end{array}$ & $\begin{array}{l}40 \\
1.041 .835 \\
338.085\end{array}$ & 116.990 & 50 & 55 & 116.990 \\
\hline
\end{tabular}

*Valores expressos em unidades monetárias 
No modesto exemplo exposto, o fornecedor está financiando as compras da mesma forma, porém, como as entregas foram escalonadas, a empresa compradora pode diluir o valor comprado com desembolsos menores e mais adequados a um fluxo mais contínuo de pagamentos. Neste exemplo, os fluxos de pagamentos decorrentes, com impostos e outros não estão especificados e, além do mais, verifica-se que se evita o risco de, inadvertidamente, comprar prioritariamente produtos com valores que gerem prejuízo. Esse conjunto de fatores gera melhores condições de ações corretivas a se implementar principalmente em momentos de adversidade.

Assim, é possível entender que, dependendo do modelo de cálculo adotado para as compras, pode-se ter diferenças muito grandes para a administração do capital de giro da empresa e, consequentemente, desdobramentos no resultado financeiro conseguido.

Wanke (1999) traz uma reflexão acerca dos pontos de reabastecimento em função do parâmetro incerteza com dois gráficos ilustrativos (abaixo).

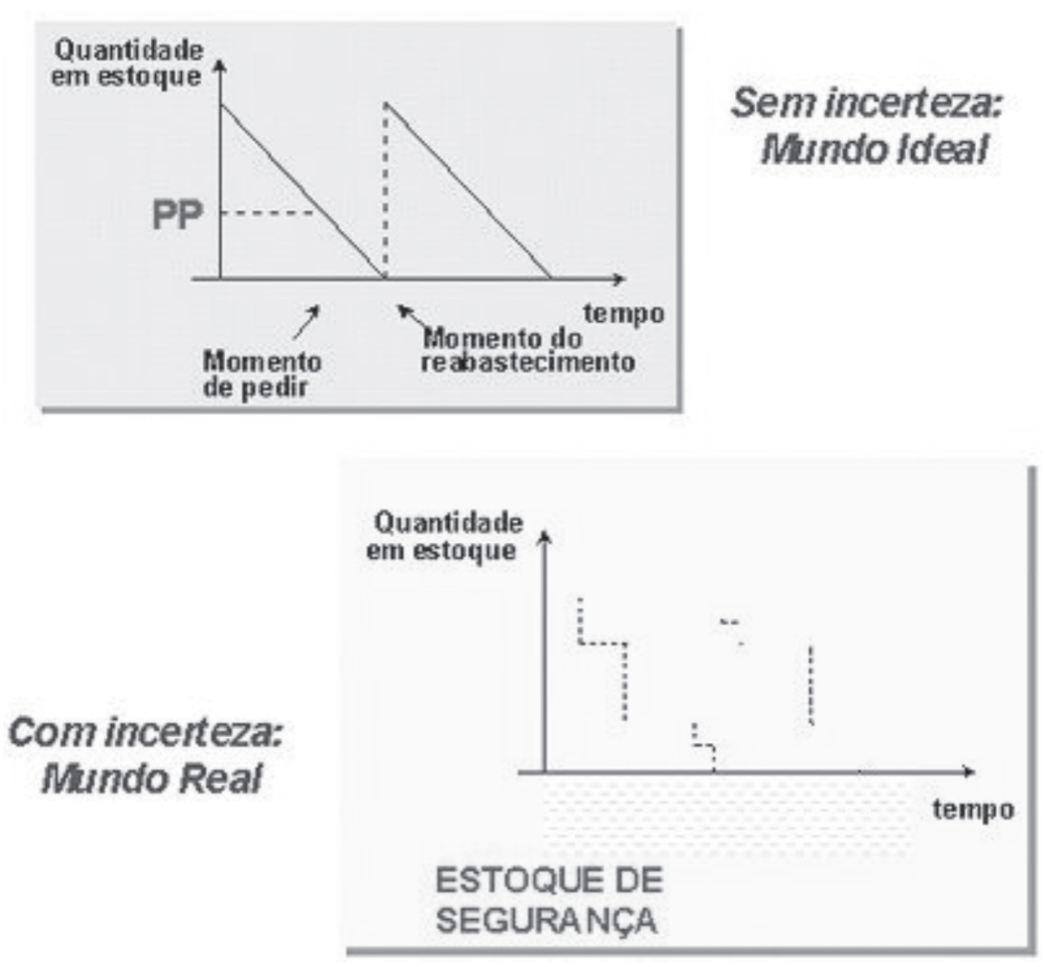

Figura 3. Modelagem do consumo de materiais

Analisando visualmente o quadro acima, percebese claramente a falta de regularidade no reabastecimento durante o tempo, quando existe incerteza (mundo real). Mas não é somente a incerteza que traz irregularidade no abastecimento, também a política de reposição adotada estrategicamente pela empresa o faz.

Com essas informações, fica claro entender que, na hora da compra e da negociação com os fornecedores, a empresa possua uma metodologia própria para usar na aquisição de produtos, com vistas a atingir seus melhores resultados. Demonstra-se, assim, a capacidade de seus condutores em transformar as incertezas.

\section{Gerenciamento de compras}

A empresa pode ter um poder de barganha diferenciado em função do porte das empresas, e, também, das metas empregadas pelos seus administradores para serem atingidas de acordo com 
as reais possibilidades da empresa. Ainda assim, esta deve ter domínio sobre as tarefas a serem executadas na operacionalização das compras, políticas próprias e estratégias desenvolvidas de acordo com o planejamento de suas atividades.

Qual então é a metodologia que dá apoio a essas decisões?

"É necessário que a empresa estabeleça um processo de gestão integrada aos negócios empresariais, estruturada para o aperfeiçoamento da qualidade e, por conseguinte, para sua almejada competitividade." (MORI; SILVA, 2003, p.38). Ressalto que os autores acima evidenciam a competitividade da empresa como consequiência do aperfeiçoamento de sua gestão de processos e de qualidade.

Para cada ramo de negócio, pode existir uma forma que melhor se adapte às compras. Essa integração sistêmica é primordial para que as compras sejam eficientes. Observa-se o seguinte:

Evita-se com isso prejuízos por ineficiência de negociações, paralizações da linha de produção por falta de materiais e outros prejuízos que poderão ocorrer, inclusive relativos à atuação do próprio pessoal envolvido no fluxo de aquisição de materiais. Nesse fluxo ocorre uma integração de:

a) Departamento de Produção

b) Departamento de Almoxarifado

c) Departamento de Compras

(JACINTHO, 1983)

Preliminarmente, porém, a integração acima exposta está diretamente relacionada com as funções exercidas por esses departamentos no momento das compras. Em empresas do mesmo ramo, porém, o estilo de compras pode diferir em função do porte, visto que a capacidade financeira, de estocagem e de vendas diferem até mesmo entre empresas concorrentes no mesmo setor de atividades, e isso pode ter como reflexo, preços diferentes para o consumidor, mesmo a partir de um mesmo preço de compra. Por isso, todos administradores têm de saber quais são as maneiras integradas de análise e a prioridade na sua forma de uso, para calcular e decidir uma compra de estoques que minimize as perdas financeiras e maximize os lucros na gestão dos estoques. Além disso, eles devem estabelecer a seqüência lógica de decisões, vinculadas às suas estratégias competitivas, e essa seqüência deve ser obedecida no momento de se fazer uma compra. Do mesmo modo eles devem saber negociar com fornecedores, mesmo numa posição de desvantagem em relação à concorrência. Eis aqui um exemplo de cultura aplicado à administração, dado por Moura (1999, p.13): "Estoque, do ponto de vista japonês, é um desperdício. Desperdício de dinheiro e espaço." E ainda continua Moura (1999, p.13): "As despesas financeiras hoje existentes, acrescidas dos riscos de obsolescência, decorrentes de um mercado altamente dinâmico, obrigam as empresas a operar com estoques extremamente reduzidos em todos os níveis." Para Horngren (1989, p.680) "Os estoques são proteções (1) que absorvem erros de planejamento e flutuações imprevistas de oferta e procura, e (2) que facilitam a fluência das operações de produção e comercialização."

Assim, a empresa deve ser capaz de saber como gerir seu capital de giro; como e porque aumentar o giro com estoques, aplicando técnicas como o Justin-Time; em que aplicar os recursos financeiros disponíveis e em que proporções, com relativa segurança; e também como negociar com cada um de seus fornecedores, de acordo com o conhecimento da metodologia aplicada à reposição de cada mercadoria da empresa. Insere-se neste contexto a explicação de Di Agustini (1999, p.54): "Certamente a fonte de recursos mais saudável de capital de giro para a empresa deve ser oriunda das suas atividades operacionais, principalmente quando o fluxo operacional e financeiro permite a formação de capital de giro próprio.", ou seja, o bom gerenciamento da empresa.

Em alguns casos, infelizmente, o custo do capital de terceiros para financiamento de estoques e vendas durante o ciclo operacional, pode representar a parcela de lucro dos produtos quando vendidos. 
Exemplos mais comuns desses financiamentos, realizados por instituições financeiras e outros, são os descontos de duplicatas e adiantamento a cheques pré - datados.

Franco (1989, p.306) relata que: “[...] quanto maior o número de vezes que o estoque circular num ano, maior o rendimento obtido pela empresa sobre o capital aplicado em estoque".

Esta afirmação, também feita por outros autores dentro do contexto de JIT, em parte é verdadeira. Porém, se os produtos que a empresa mais fizer circular gerarem prejuízo, a cada compra este prejuízo aumentará e isso contribuirá negativamente para a formação de capital de giro próprio. Esse fato também ocorrerá, se a empresa comprar sem a devida adequação ao fluxo de caixa, pagando à vista por um produto e comercializando-o à prazo, sem ter as possibilidades de financiar esta venda. O que foi dito justifica-se porque o tratamento das entradas e saídas de caixa no fechamento de cada dia deve ser suficiente para saldar todos os compromissos assumidos pela firma naquele período. $\mathrm{O}$ financiamento de vendas aos clientes, bancado pela empresa ou por terceiros, pode, em muitos casos, contribuir para a não - efetivação dos lucros esperados. E pior, pode conduzir a empresa para uma situação de insolvência. Considere-se, então, quando todas estas condições negativas estão presentes e o empresário não dispõe de meios sistêmicos para combatê-las. Pergunta-se então: qual poderá ser o resultado?
Esta situação na administração leva, muitas vezes, o empresário a alterar o modelo administrativo tradicional de compras, com relação às suas parcerias. Atualmente, diversos ramos comerciais e industriais têm seu fornecedor, atuando diretamente no cliente numa tentativa de diminuir os custos de administração, aumentar o giro nos estoques e não gerar custos financeiros no decorrer da compra. Aí, a empresa aumenta o prazo das compras quando exige da parceira a mercadoria, por exemplo, ou produto industrializado na prateleira para comercialização, numa forma de administração que faz aumentar a confiança no fornecedor. $\mathrm{O}$ aumento da confiança nos fornecedores geralmente diminui as formas de controle, diminuindo custos. Em algumas empresas, principalmente em indústrias, cabe levar em conta o ciclo de produção e custos de fabricação, desde a compra da matéria-prima até a efetivação do recebimento do dinheiro de uma mercadoria vendida.

Trata-se de um problema de equacionamento difícil de resolver, pois ele necessita de muito empenho dos administradores.

Gerir estes conflitos, sempre de forma simples, rápida e eficaz, é uma qualificação difícil e sempre desejada por quem bem administra. Ou esperada por seus patrões.

Existem muitas técnicas que podem auxiliar a maximização dos resultados da empresa como um

Tabela 4. Simulação de compras antecipadas

\begin{tabular}{|c|c|c|c|c|c|c|}
\hline A & B & $\mathrm{C}$ & $\mathrm{D}$ & $\mathrm{E}$ & $\mathrm{F}$ & $\mathrm{G}$ \\
\hline custo unit. & $\mathrm{M}=$ meses & $\mathrm{k}=\%$ aum & $\mathrm{j}=\mathrm{tx}$. mês & Consumo & $A \times G$ & $B \times E$ \\
\hline 100 & 15 & $30 \%$ & $2 \%$ & 300 & 150000 & 1500 \\
\hline 300 & 4 & $8 \%$ & $2 \%$ & 289 & 346800 & 1156 \\
\hline 250 & 7,5 & $15 \%$ & $2 \%$ & 789 & 14793750 & 59175 \\
\hline 700 & 3 & $6 \%$ & $2 \%$ & 980 & 2058000 & 2940 \\
\hline 20 & 5 & $10 \%$ & $2 \%$ & 700 & 70000 & 3500 \\
\hline 100 & 6 & $12 \%$ & $2 \%$ & 10 & 6000 & 60 \\
\hline 240 & 1 & $2 \%$ & $2 \%$ & 590 & 141600 & 590 \\
\hline 900 & 25 & $50 \%$ & $2 \%$ & 5 & $90.000,00$ & 100 \\
\hline 10 & 1 & $2 \%$ & $2 \%$ & 12900 & 129000 & 12900 \\
\hline \multicolumn{5}{|c|}{ Total do lote sem alterações analíticas } & \multicolumn{2}{|l|}{17785150} \\
\hline
\end{tabular}


sistema, e algumas delas antigas como a classificação $\mathrm{ABC}$, em relação ao Kanban, por exemplo, porém não menos importante para o conjunto do gerenciamento dos estoques. No entanto, ainda permanece a dúvida pelo fato de as empresas, de modo geral, não as utilizarem de forma rotineira?

\section{Compras Antecipadas}

No uso da fórmula de compras antecipadas, as citações especificadas na revisão bibliográfica deste trabalho devem ser consideradas, e parte-se do princípio de que se está trabalhando com capital próprio. Apresenta-se, então, a simulação abaixo como ilustração.

Se colocarmos algumas condições limitantes como: quantidade máxima para se armazenar; capital disponível para se fazer compras no período mensal; capacidade de fornecimento, o exemplo acima mudará consideravelmente. Esta tarefa deve ser sempre realizada de modo integrado na administração da empresa.

\section{Modelo Sistêmico Integrado na Gestão de Estoques e Compras (MSIGEC)}

O modelo sistêmico de compras aqui apresentado pressupõe a circulação das informações necessárias à tomada de decisão (sistematização) entre as diversas áreas da empresa e, internamente, em cada departamento envolvido. Essas áreas estão relacionadas hierarquicamente, para que se defina a ordem de prioridade e, de acordo com o princípio da interação sistêmica, possa haver sincronia entre as ações efetuadas.

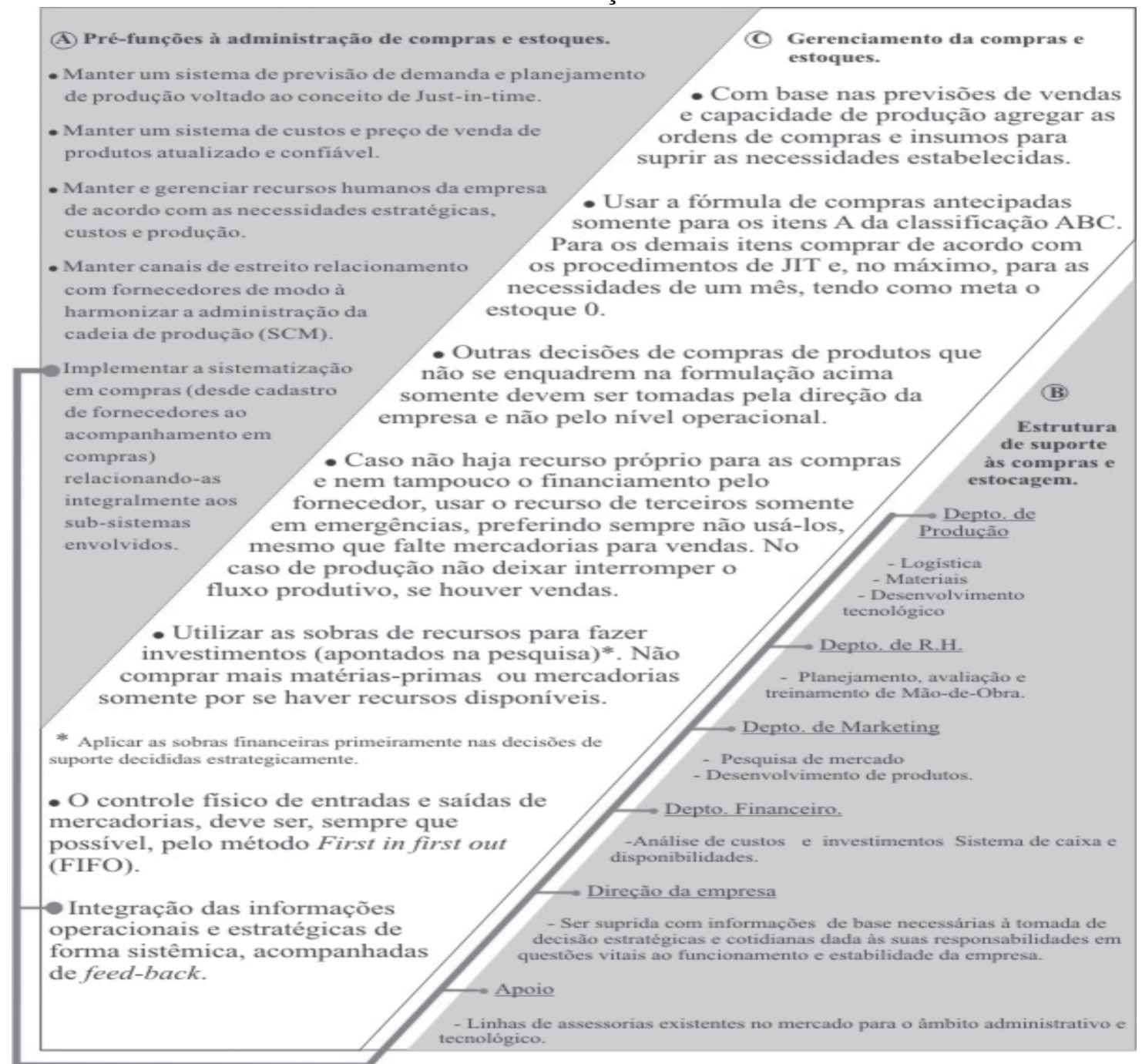

Figura 4. Modelo sistêmico integrado (MSIGEC) 


\section{Especulação (Vantagens e Desvantagens)}

Algumas vantagens da especulação são citadas a seguir:

- Poder alcançar vantagens financeiras maiores que os outros participantes da cadeia produtiva.

- Obter status pelo acúmulo de riquezas.

- Ditar preços e condições na comercialização de produtos.

- Estabelecer um "jogo" em mercados futuros.

- Regular o fluxo de venda de produtos.

No entanto, podem ser apontadas as seguintes desvantagens:

- Manter condições logísticas para estocagem.

-Manter capitais próprios e de terceiros disponíveis em alto volume.

- Ter grandes perdas caso a estimação de preços futuros não se realize.

-Não ter o comprometimento com parceiros na cadeia produtiva.

A especulação, como forma para atingir resultados sistêmicos, gera erros e falsos parâmetros de administração, decorrentes de ações equivocadas no curto, médio e longo prazo.

\section{Metodologia}

Apresenta-se a seguinte fundamentação metodológica, inicialmente formulada por Pádua (1997, p.29): "Tomada num sentido amplo, pesquisa é toda atividade voltada para a solução de problemas; como atividade que busca, indagação, investigação, inquirição da realidade, é a atividade que vai nos permitir, no âmbito da ciência, elaborar um conhecimento, ou um conjunto de conhecimentos, que nos auxilie na compreensão desta realidade e nos oriente em nossas ações."

Galliano (1986, p.6), por sua vez, escreve: "MÉTODO é um conjunto de etapas, ordenadamente dispostas, a serem vencidas na investigação da verdade, no estudo de uma ciência ou para alcançar determinado fim." E acrescenta: "TÉCNICA é o modo de fazer de forma mais hábil, mais segura, mais perfeita algum tipo de atividade, arte ou ofício."

No intuito de atingir os objetivos propostos para esta pesquisa e a partir de idéias conjecturais do pesquisador a respeito do assunto, partiu-se do princípio que existe uma associação entre as variáveis que compõem a administração de compras no conjunto da administração do capital de giro da empresa e a efetivação do lucro. A partir dessas idéias, elaborou-se um conjunto de hipóteses para serem testadas estatisticamente, averiguando-as em seguida e obtendo-se as respostas.

\section{Hipóteses Estabelecidas}

H0 - O nível de estoque que a empresa pratica em períodos de alta inflação é maior que nos períodos de baixa inflação.

H1 - O nível de estoque que a empresa pratica em períodos de alta inflação não é maior que nos períodos de baixa inflação.

HA - Existe diferença no lucro realizado pela empresa e o volume de capital disponível nos períodos de alta inflação e baixa inflação.

HB - Não existe diferença no lucro realizado pela empresa e o volume de capital disponível nos períodos de alta inflação e baixa inflação.

\section{Técnica de Trabalho}

A coleta de dados foi realizada por meio de instrumento próprio (ficha anexa simplificada), com base nas informações dos balanços publicados por empresas no Diário Oficial do Paraná. O universo pesquisado foi aleatoriamente amostrado para os anos especificados, nos meses de fevereiro, março e abril, preferencialmente.

Tomou-se, como amostra, o balanço de 164 empresas, comerciais e industriais. Dessas, $88 \mathrm{em}$ períodos de alta inflação no Brasil, (1982 a 1984) e 73 em períodos de baixa inflação (1997 a 1999), e 
procurou estabelecer-se uma relação entre o perfil de formação de estoques naqueles períodos e outros itens financeiros demonstrados nos balanços.

Em épocas tanto de alta como de baixa inflação, o mercado de capitais brasileiro paga correções monetárias equivalentes à inflação, mais juros, respectivamente para os períodos relacionados. Desse modo, procurou analisar-se nestes dois períodos, quais foram os resultados obtidos pelas empresas na administração dos estoques e no conjunto da administração do capital de giro.

Porém, o balanço é a representação de um momento numérico e estático e não de uma apresentação da condição dinâmica da administração dos estoques. Isso significa, analogamente, retratar fotograficamente carros em movimento no trânsito urbano. Tem-se, como resultado, a visualização de um momento, porém não se pode fazer inferências a respeito de outras características técnicas daqueles automóveis como, situação legal, estado de conservação, combustível utilizado, etc. Além disso, os balanços, podem conter erros nas suas demonstrações, de modo que se tomou o cuidado de não se incluir, no universo amostrado, os dados de balanços que tecnicamente continham erros. Outro alerta, entre tantos, que se deve ter com relação ao que se apresenta numa demonstração contábil é o que está relatado no artigo da Gazeta Mercantil:
"Depois dos recentes escândalos envolvendo manipulações de balanço da Enron, WorldCom e Xerox, aumentou o interesse das empresas em apresentar transparência nas suas operações" (ESCÂNDALOS..., 2002, p.3).

Embora a amostra coletada tenha sido aleatória, observou-se, coincidentemente, que muitas empresas amostradas em períodos de baixa inflação também fizeram parte do conjunto amostrado em períodos de alta inflação, talvez em função de a época de publicação de seus balanços serem as mesmas.

Aplicou-se aos valores numéricos expostos nos balanços, após serem relativizados, o teste $t$ de student para duas amostras, presumindo-se variâncias diferentes em relação à significância de alfa $=0,05$. Os valores apresentados nos balanços: lucro/vendas; estoque/ativo circulante e disponível/ativo circulante foram então analisados estatisticamente, gerando índices.

\section{Tratamento Estatístico}

Abaixo estão representados os dados nos períodos de alta inflação com a inscrição "com" e os períodos de baixa inflação com a inscrição "sem", com a legenda: e/at.c=estoque/ativo circulante; at/ dis= ativo circulante/disponível; lu/vem= lucro/ vendas; dis/at.c= disponível $/$ ativo circulante; esdis at.c= estoque+disponível/ ativo circulante.

Tabela 5. Tratamento estatístico

\begin{tabular}{|l|l|l|l|l|l|l||l|l|}
\hline & come/at.c & seme/at.c & comat/dis & semat/dis & Comlu/ven & semlu/ven & comdis/at.c. & semdis/at.c \\
Média & 41,49856 & 35,88362 & 51,30829 & 50,96475 & 7,790076 & 0,976636 & 9,809733518 & 15,08112977 \\
Erro padrão & 1,974758 & 2,182854 & 2,05706 & 2,62268 & 1,384863 & 1,046405 & 1,137929733 & 2,169539544 \\
Mediana & 43,4411 & 34,62051 & 50,99616 & 47,48367 & 7,96785 & 1,149425 & 6,151719114 & 6,256627784 \\
Desvio padrão & 18,52487 & 18,65031 & 19,29693 & 22,40819 & 12,99117 & 8,940489 & 10,67472711 & 18,53655399 \\
Variância da & 343,1708 & 347,8341 & 372,3715 & 502,1269 & 168,7704 & 79,93235 & 113,9497989 & 343,6038339 \\
amostra & 0,593361 & 0,1697 & 0,041748 & $-0,71476$ & 2,198478 & 3,653223 & 5,352488531 & 2,676239569 \\
Curtose & 0,300856 & 0,442889 & 0,093185 & 0,372956 & $-0,7752$ & $-0,75391$ & 2,092825268 & 1,796093281 \\
Assimetria & 89,80551 & 86,8527 & 92,65945 & 90,82371 & 78,23324 & 59,11202 & 59,22752061 & 77,98246288 \\
Intervalo & 4,07332 & 3,769841 & 6,569343 & 9,176288 & $-40,4181$ & $-33,1162$ & 0,000874453 & 0,182094082 \\
Mínimo & 93,87883 & 90,62254 & 99,22879 & 100 & 37,81513 & 25,99581 & 59,22839506 & 78,16455696 \\
Máximo & 3651,873 & 2619,504 & 4515,13 & 3720,427 & 685,5267 & 71,29441 & 863,2565496 & 1100,922473 \\
Soma & 88 & 73 & 88 & 73 & 88 & 73 & 88 & 73 \\
Contagem & 88 & & 78 \\
\hline
\end{tabular}


Modelo sistêmico integrado em gestão de estoques e compras na administração de resultado: o desafio financeiro no ressuprimento

Tabela 6. Teste t de student para duas amostras, presumindo-se variâncias diferentes.

\begin{tabular}{|c|c|c|c|c|c|}
\hline Média & Come/at.c & $\begin{array}{l}\text { seme/at.c } \\
3588362\end{array}$ & Média & comesdis/at.c & semesdis/at.c \\
\hline Variância & 343,1708 & 347,8341 & Variância & 372,3715 & 502,1269 \\
\hline Observações & 88 & 73 & Observações & 88 & 73 \\
\hline $\begin{array}{l}\text { Hipótese da diferença de } \\
\text { média }\end{array}$ & 0 & & $\begin{array}{l}\text { Hipótese da diferença de } \\
\text { média }\end{array}$ & 0 & \\
\hline Gl & 153 & & Gl & 143 & \\
\hline Stat $\mathrm{t}$ & 1,907537 & & Stat $\mathrm{t}$ & 0,103069 & \\
\hline $\mathrm{P}(\mathrm{T}<=\mathrm{t})$ uni-caudal & 0,029162 & & $\mathrm{P}(\mathrm{T}<=\mathrm{t})$ uni-caudal & 0,459026 & \\
\hline t crítico uni-caudal & 1,654874 & & t crítico uni-caudal & 1,655579 & \\
\hline $\mathrm{P}(\mathrm{T}<=\mathrm{t})$ bi-caudal & 0,058325 & & $\mathrm{P}(\mathrm{T}<=\mathrm{t})$ bi-caudal & 0,918053 & \\
\hline t crítico bi-caudal & 1,97559 & & t crítico bi-caudal & 1,976692 & \\
\hline
\end{tabular}

\begin{tabular}{|l|l|l|l|l|l|}
\hline Média & comlu/ven & semlu/ven & & comdis/at.c & semdis/at.c \\
Variância & 7,790075906 & 0,976635779 & Média & 9,809734 & 15,08113 \\
Observações & 168,7704253 & 79,93234784 & Variância & 113,9498 & 343,6038 \\
Hipótese da diferença de & 88 & 73 & Observações & 88 & 73 \\
média & 0 & & Hipótese da diferença de & & \\
Gl & 154 & média & 0 \\
Stat $\mathrm{t}$ & 3,925370138 & & Gl & 110 \\
$\mathrm{P}(\mathrm{T}<=\mathrm{t})$ uni-caudal & $6,51204 \mathrm{E}-05$ & & $-2,15172$ & \\
$\mathrm{t}$ crítico uni-caudal & 1,654808386 & Stat t & 0,016803 & \\
$\mathrm{P}(\mathrm{T}<=\mathrm{t})$ bi-caudal & 0,000130241 & $\mathrm{P}(\mathrm{T}<=\mathrm{t})$ uni-caudal & 1,658824 & \\
$\mathrm{t}$ crítico bi-caudal & 1,975488024 & $\mathrm{t}$ crítico uni-caudal & 0,033607 & \\
\hline
\end{tabular}

Abaixo temos a visualização gráfica do resultado, para efeitos de comparação, nos períodos de baixa e alta inflação, dos valores relativizados e estatisticamente tratados, de disponibilidades/ativo circulante; estoques/ativo circulante e lucro/vendas. Demonstra-se visualmente a inversão em que, com menos dinheiro disponível para aplicação financeira, houve significativamente maior lucro em períodos de alta inflação.

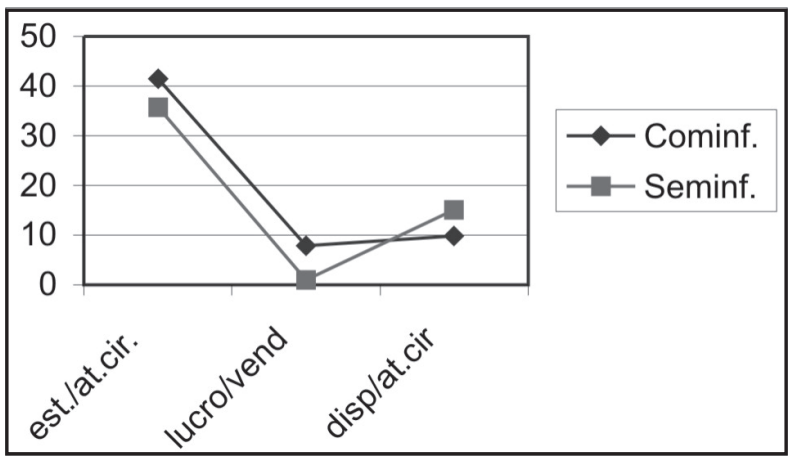

Figura 5. Comparação estatística

\section{Abordagem Crítica}

Após ter sido feito o tratamento estatístico, observou-se que, para o período de inflação alta, comparativamente ao período de baixa inflação, as empresas tiveram uma tendência a aplicar mais recursos em estoques e menos recursos em disponibilidades para caixa e aplicações financeiras. Porém, quando se observa o resultado alcançado efetivamente, mesmo com menos disponibilidades, tem-se, estatisticamente, um resultado significativo melhor em termos de lucro nas empresas em períodos de alta inflação. Mas, matematicamente, não se pode afirmar que a estratégia de estocar mais foi a determinante para se obter mais lucro nos períodos de alta inflação. Este lucro maior é, provavelmente, devido ao fato de as empresas terem um nível de retorno maior nas aplicações financeiras realizadas. Nos períodos de baixa inflação, mesmo com maior 
disponibilidades de recursos para este tipo de aplicação, o lucro foi menor. Ou seja, não se pode afirmar que o maior volume aplicado em estoques foi a estratégia que resultou em mais lucros, mesmo sendo esta a tendência adotada genericamente pelas empresas em períodos de alta inflação.

Estes resultados mostraram, no geral, a indicação à interdependência dos valores aplicados num sistema empresarial tradicional de produção e de comercialização e suas limitações na empresa quando vistas de uma forma holística, em função da estratégia de investimento adotada.

Abre-se aqui uma explicação cientificamente necessária. Na primeira verificação estatística, comprovou-se, pelo mesmo teste t de student, haver significativamente maior estocagem em períodos de inflação elevada. Posteriormente, 3(três) itens da amostra foram retirados por não estarem tecnicamente compatíveis, e disso resultou, finalmente, um índice de $94,16 \%$. Com mais $0,85 \%$, apenas, ter-se-ia, no nível de significância de 5\%, a comprovação da hipótese H0: o nível de estoque que a empresa pratica em períodos de alta inflação é maior que nos períodos de baixa inflação. Essa hipótese foi, posteriormente, rejeitada.

A alta variância da amostra e a circunstância de serem empresas de ramos diferentes e porte desigual leva ao estabelecimento de outra inferência estatística nos balanços publicados: existiu uma semelhança nas ações de administração do capital de giro, incluindo aí a formação de estoques. Esses fatos reforçam a idéia de agregação de fatores produtivos em função das vendas ou produção e as relações decorrentes de tais ações no sistema empresarial de administração. Isso é facilmente confirmado com exemplos simples, vistos no dia a dia de todos nós quando, por exemplo, existem mais contratações de funcionários quando se aumentam vendas e viceversa. Em outros termos, a aplicação às prioridades de administração agrega, em sua lógica, fatores decorrentes e associados e pode-se associar esta lógica sistêmica à construção de um modelo ERP.
Um outro exemplo para ilustrar esta interdependência e limitação de ações que o sistema produtivo de resultados da empresa oferece é o seguinte: não bastaria o administrador querer aplicar mais recursos em estoques, tanto em épocas de alta como em baixa inflação, porque ele estaria sempre limitado às possibilidades de caixa, tratadas em seu fluxo de entradas e saídas. Numa suposição de que estas disponibilidades sejam muito grandes, ainda assim ele estaria limitado pela capacidade de armazenamento e de distribuição de mercadorias (logística aplicada). Porém, deve-se ressaltar que, mesmo existindo uma tendência a se estocar mais em momentos de alta inflação ou de incertezas, esta estocagem é limitada e não traz a certeza de realização de lucro. O que foi dito fortalece o seguinte ponto: na busca da otimização de recursos, e da maximização dos resultados, existe um limite e uma correlação de fatores entre os valores que são alocados para cada área da empresa, também a considerar que estas empresas, já, desenvolvidas na sua maioria. Hipoteticamente, insistir nesta forma de gerenciamento seria uma inversão ao propósito capitalista, gerando distorção ao ritmo balanceado que corresponde à capacidade daquele "sistema empresarial.

A título de ilustração, as médias de estoques encontradas em relação ao faturamento anual foram respectivamente, para os períodos de alta inflação e baixa inflação, 19,08\% e 13,80\%. Essas médias não podem ser tomadas como referências taxonômicas operacionais, devido à alta variância dos dados amostrados e ao fato de as microempresas não fazerem parte da amostra, já que apenas as empresas S.A. publicam seus balanços obrigatoriamente no Diário Oficial. Esses dados, porém, abrem perspectivas de exploração, em função do lucro obtido naqueles períodos.

Outros questionamentos podem ser feitos: por que as empresas em períodos atuais, de baixa inflação, não aumentaram o lucro? Ora, é de se esperar que seus empresários tenham aplicado as técnicas de administração e de gerenciamento que surgiram, 
como as normas de controle de qualidade e ambiental ISO (INTERNATIONAL ORGANIZATION FOR STANDARTIZATION), no intuito de modernizarem suas empresas. Outra técnica relacionada à gestão dos estoques que pode ser citada neste contexto é o método KANBAN:

KANBAN é um método que reduz o tempo de espera, diminuindo o estoque, melhorando a produtividade $\mathrm{e}$ interligando todas as operações em um fluxo uniforme e ininterrupto. O principal objetivo: Conversão de matéria-prima em produtos acabados, com tempos de espera iguais aos tempos de processamento, eliminando todo o tempo em fila do material e todo o estoque ocioso. (MOURA, 1999, p.27)

Será, então, que o maior determinante da lucratividade está associado a aplicações em mercados de capitais que rendem ganhos maiores que a atividade operacional da empresa? Ou o lucro obtido no período de alta inflação não pode ser tomado como referencial de lucratividade para outros períodos? Outra questão: que fatores levam as empresas atualmente a não terem o mesmo nível de lucratividade como nos períodos de alta inflação?

Na lógica da administração, isso é um contrasenso. Pois, quando existia alta inflação, a opinião quase unânime era de ela ser um "dragão" que corroia salários, diminuía lucros e aumentava as despesas financeiras, trazendo quase sempre conseqüências indesejadas. Quando a inflação se estabilizou, o que se verificou foi a diminuição de lucro para todo o conjunto de empresas.

Surge, então, a necessidade de se verificar no conjunto sistêmico da empresa o seu dimensionamento, tanto no sentido de condições de produção e de vendas, como também dos seus serviços de apoio administrativo, equacionando os recursos aplicados em cada área, equilibradamente.

\section{Conclusões e Recomendações}

$\mathrm{Na}$ administração de compras, dentro do contexto de administração do capital de giro, sempre é desejável ter o volume possível de capital de giro próprio para financiar as atividades necessárias. Para se conseguir este feito, ao realizar compras, deve-se optar entre o modelo tradicional de administração de estoques e os modernos modelos, como o JIT, por exemplo. A partir daí, as decisões de compras estarão vinculadas a um sistema. Estrategicamente, de acordo com cada ramo de atividade, o empresário deve então estar ciente dos procedimentos operacionais de cada sistema e dos resultados que os mesmos poderão adicionar na busca da maximização e otimização dos recursos da empresa.

Nesta pesquisa também se obteve, por meio dos testes estatísticos realizados, a comprovação das seguintes hipóteses estabelecidas:

$$
\begin{aligned}
& \text { H1 - O nível de estoque que a empresa } \\
& \text { pratica em períodos de alta inflação não } \\
& \text { é maior que nos períodos de baixa } \\
& \text { inflação. } \\
& \text { HA -Existe diferença no lucro realizado } \\
& \text { pela empresa e o volume de capital } \\
& \text { disponível nos } \\
& \text { períodos de alta inflação e baixa inflação. }
\end{aligned}
$$

Todavia, em função do resultado do teste $\mathrm{t}$ de student, para o nível dos estoques nos períodos amostrados, deve-se ter muito senso crítico na análise e, principalmente, na aplicação desses resultados.

Pode-se verificar, no contexto bibliográfico, a inadequação ao uso prático da utilização das fórmulas matemáticas de LE. Isto em função do volume de capital de giro necessário para sua manutenção.

E ainda gerou um questionamento: qual empresa atualmente utiliza somente a fórmula de Lote Econômico de Compras (LEC) para calcular o quanto comprar num determinado período de forma sistêmica e rotineira, para o conjunto de seus produtos, mesmo no modelo tradicional de administração?

Observou-se que a prática da especulação e fórmula de compras antecipadas, usada no modelo 
tradicional de gestão de estoques, contribui para obter ganhos financeiros maiores a curto prazo. Porém, o uso de tal prática revela-se inadequada quando se empregam técnicas modernas de administração da produção (como o JIT), as quais permitem tratar aos fornecedores como coparticipantes do esforço de produção.

Na realização da compra de produtos, quer seja para industrialização, quer para a comercialização, deve ter-se em mente que se está operacionalizando um sistema empresarial, ou seja, não se trata da aquisição unilateral de produtos de fornecedores. Nesta visão, a hierarquia sistêmica de administração e suas prioridades têm de ser observadas, para obterse o melhor resultado possível. Os resultados são alcançados a partir de ações conjuntas e equilibradas, definidas de acordo com a sensibilidade do administrador. Para facilitar este conjunto de decisões, o modelo exposto neste trabalho ( chekc-list das compras) pode auxiliar.

Mas, antes de tudo, é necessário que a empresa defina claramente sua política de compras, optando, de acordo com o seu ambiente empresarial e o mercado, entre o modelo tradicional de compras e os modelos modernos, como o JIT. Este último é uma tendência atual da administração, embora se revele mais complexo na sua forma de execução a curto prazo. Isso se define estrategicamente como "Coresponsabilidades Integradas em Manufaturas (CIM)" e é valido para o conjunto da cadeia de produção e consumo.

Para se ter uma classificação taxonômica dos níveis de estoque, recomenda-se que, a partir deste estudo, sejam feitos outros, sempre se explorando cada atividade separadamente. Assim, pode-se chegar a classificações de estoque para cada ramo, expondo-se suas características mais peculiares, inclusive em função de diferentes estratégias seguidas para as diversas fases no desenvolvimento de cada empresa e políticas de compras adotadas, e que sejam evidenciadas no contexto de produtividade da empresa.
Também se recomenda que a técnica de trabalho (estatístico/metodológica) aqui formulada e desenvolvida seja aplicada por outros pesquisadores, em outros estados do Brasil e até mesmo outros países que possuam características econômicas semelhantes a nossa. Com isso, poder-se-á testar a validade externa desta técnica.

Será possível, assim, obter benefícios em ter parâmetros de administração de estoques para consulta por empresários e estudantes interessados no assunto, com dados que auxiliam a tomada de ações. Esses dados, porém, devem ser específicos ao seu ramo de atuação, considerando o porte das empresas, como os publicados por revistas de expressão nacional. Os parâmetros gerados nesta pesquisa podem ser considerados também na administração de estoques, com a devida crítica.

Foram identificados e descritos os princípios básicos referentes ao planejamento das compras e suas inter-relações sistêmicas na empresa e da empresa com o ambiente externo, por meio da apresentação de um modelo conceitual de tomada de decisão nas compras, ou seja, um check list das compras. Os procedimentos de reposição de estoques para produção e vendas foram diferenciados dos procedimentos que visam à especulação, mostrando vantagens e desvantagens. Espera-se, portanto, que, ao utilizar-se de tais instrumentos auxiliares de administração das compras, o empresário ou gestor tenha melhores critérios técnicos que, aliados ao bom senso, poderão resultar em melhores performances da empresa no aspecto financeiro e organizacional. Recomenda-se que o administrador, sabedor dos limites sistêmicos da empresa, trabalhe em função destes adequando-os aos seus conceitos de administração. É de esperar-se, também, que o uso do conhecimento técnico aqui exposto seja feito no momento correto pela empresa. Explica-se analogamente: quando um avião quer pousar, o piloto e seu co - piloto fazem antecipadamente uma série de checagens de procedimentos para que tudo saia correto. Quando as condições de tempo são adversas, esses procedimentos são mais rigorosos e pode até 
Modelo sistêmico integrado em gestão de estoques e compras na administração de resultado: o desafio financeiro no ressuprimento

existir a opção da aeronave não pousar. O mesmo deve ser feito pelo empresário rotineiramente nas compras, podendo-se decidir até mesmo por não comprar e fazer-se outro tipo de investimento. Mas é necessário que o empresário não tome estas decisões na última hora ou quando "a aeronave já estiver na cabeceira da pista".

\section{Referências}

ALCURE, S. Controle e previsão de estoque. Rio de Janeiro: Manuais CNI, 1982.

AMNER, D. S. Administração de material. Rio de Janeiro: LTC, 1979.

ARNOLD, T. J. R. Administração de materiais: uma introdução. São Paulo: Atlas, 1999.

BERGER, R. Inovação em compras redução de até $20 \%$ com impacto direto nos resultados. Ícaro: Revista de Bordo da Varig, São Paulo, n.233, p.57, jan. 2004.

BORDOKAN, J. O retorno do investimento em estoque. São Paulo: Abril Cultural, 1983

BOVET, D.; MARTHA, J. Redes de Valor: Aumente os lucros pelo uso da Tecnologia da Informação na cadeia de valor. São Paulo: Negócios, 2001.

CASADO, V. Guerra fiscal agrava mercado do leite. Folha de Londrina, Londrina, 22 nov. 2003. Folha Rural, p.5.

CHEHEBE, J. R. B. Análise do ciclo de vida dos produtos. Rio de Janeiro: Qualitymark, 2002.

CHIAVENATO, I. Introdução à teoria geral de administração. 4.ed. São Paulo: Makron Books, 1993.

CRISE do arroz dura mais seis meses. Folha de Londrina, Londrina, 9 jul. 2003. Folha Rural, p.12.
DEMO, Pedro. Metodologia científica em ciências sociais. 3.ed. São Paulo: Atlas, 1995.

DI AGUSTINI, Carlos Alberto. Capital de giro. São Paulo: Atlas.1999.

ESCÂNDALOS Contábeis motivam transparência. Gazeta Mercantil, São Paulo, 11 jul. 2002. Caderno Região Sul, p.3

FENSTERSEIFER, J. E. Modelos de estoques com aumento previsto no custo de aquisição. Revista de Administração, São Paulo, v.21, n.3, p.3-8, 1986.

FRANCO, H. Estrutura, análise e interpretação de balanços. São Paulo: Atlas, 1989.

GALLIANO, G. A. O método científico: teoria e prática. São Paulo: Harbra, 1986.

GRINOVER, A. P.; DENARI, Z. Código brasileiro de defesa do consumidor: comentado pelos autores do anteprojeto. Rio de Janeiro: Forense Universitária, 1998.

HANSEN, D. R.; MOWEN, M. M. Gestão de custos: contabilidade e controle. São Paulo: Pioneira, 2003.

HASPESLAGH, P.; NODA, T.; BOULOS, F. Números não são tudo. Exame, São Paulo, v.35, n.21, p.108, out. 2001.

HORNGREN, C. T. Contabilidade de custos: um enfoque administrativo. São Paulo: Atlas, 1989.

JACINTHO. Eduardo. Departamento de compras. Boletim Valor, São Paulo, n.58, 1983.

KOTLER, P. Marketing. São Paulo: Atlas, 1990.

MACHLINE, C. Compras, estoques e inflação. Rio de Janeiro: RAE, 1981. 
MENDES; J. V.; ESCRIVÃO FILHO, E. Sistemas integrados de gestão ERP em pequenas empresas: um confronto entre o referencial teórico e a prática empresarial. Gestão \& Produção, São Carlos, v.9, n.3, p.277-296, 2002.

MICHAELIS: moderno dicionário da língua portuguesa. São Paulo: Melhoramentos, 1998.

MORI, R. G.; SILVA, R. V. S. Gestão dos custos de qualidade nas empresas químicas do Brasil. São Paulo: RAE-FGV, 2003.

MOURA, R. A. Kanban: a simplicidade do controle da produção. 5.ed. São Paulo: IMAN, 1999.

PÁDUA, E. M. M. Metodologia da pesquisa. 4.ed. Campinas: Papirus, 1997.

PENTEADO FILHO, J. R. W. Previsão de vendas. São Paulo: Atlas, 1988.

PEREZ JUNIOR, J. H. Controladoria de gestão: teoria e prática. São Paulo: Atlas, 1997.
RODRIGUES, G. J. J. Redução de estoque em 3 dimensões. São Paulo: IMAN, 1993.

SANTI FILHO, A.; OLINQUEVITCH, J. L. Análise de balanços para controle gerencial: um enfoque sobre o fluxo de caixa e previsão de rentabilidade. São Paulo: Atlas, 1993.

SIMCSIK, T. Organização \& métodos. São Paulo: Makron Books, 1992.

SMITH, E. A. Manual da produtividade. Rio de Janeiro: Quality Mark, 1993.

WANKE, P. Aspectos fundamentais da gestão de estoques na cadeia de Suprimentos. Artigos CEL, Rio de Janeiro, 1999. Disponível em: <http:// www.cel.coppead.ufrj.br/fs-busca.htm?frpublic.htm>. Acesso em: 11 maio 2005.

ZERMATI, P. A gestão de Stocks. 5.ed. Lisboa: Presença, 2000.

Anexo 1. Ficha de coleta de dados (simplificada)

\begin{tabular}{|c|c|c|c|c|c|c|c|}
\hline FICHA DE & COLETA DF & DADOS D & PESQU & SA No. & & & No. \\
\hline EMPRESA & T. ATIVO & ATIVO C. & PASS.C & DISPON. & ESTOQ. & FAT. T & LUCRO \\
\hline & & & & & & & \\
\hline & & & & & & & \\
\hline & & & & & & & \\
\hline & & & & & & & \\
\hline & & & & & & & \\
\hline & & & & & & & \\
\hline & & & & & & & \\
\hline & & & & & & & \\
\hline & & & & & & & \\
\hline & & & & & & & \\
\hline & & & & & & & \\
\hline & & & & & & & \\
\hline & & & & & & & \\
\hline & & & & & & & \\
\hline
\end{tabular}

